\title{
The effects of a home exercise programme on the exercise endurance of children infected with HIV
}

\author{
C N Naidoo, MSc Physiotherapy; N Benjamin-Damons, PhD Physiotherapy; R Strehlau, MSc, MB BCh; \\ J Potterton, PhD Physiotherapy
}

Department of Physiotherapy, Faculty of Health Sciences, University of the Witwatersrand, Johannesburg, South Africa

Corresponding author: C N Naidoo (candicenoellenaidoo@gmail.com)

\begin{abstract}
Background. Human immunodeficiency virus (HIV) infection can negatively affect the exercise endurance of children. There is a lack of studies investigating the effects that home exercise programmes (HEPs) have on the exercise endurance of children in South Africa who are HIV infected.

Objective. To investigate the effects of a HEP on the exercise endurance of children infected with HIV.

Methods. The study was conducted at a paediatric HIV treatment clinic in Johannesburg. Sample size calculations were done using the Excel sample size calculator for continuous variables. Participants were randomised into two groups using a random number table. One group underwent a 12-week HEP while the control group continued with standard care. Exercise endurance was assessed using the sixminute walk test $(6 \mathrm{MWT})$ at baseline and after 12 weeks. The total distance walked was compared between groups.

Results. Sixty-two children infected with HIV between the ages of seven and nine years were enrolled. After 12 weeks, the distance walked by children who had done the HEP increased, but no significant differences were found between and within the groups' six-minute walk distance (6MWD) at baseline or at 12 weeks' follow-up. Boys walked significantly further than girls (boys: $449.15 \mathrm{~m}$; girls: $412.46 \mathrm{~m}$, $p=0.04)$ at baseline, regardless of the group.

Conclusion. There was no significant difference in walking distance between the two groups. A HEP with different components and of longer duration may yield better results. Further research is needed on the impact that a HEP could have on the exercise endurance of South African children infected with HIV.
\end{abstract}

S Afr J Child Health 2020;14(4):174-179. https://doi.org/10.7196/SAJCH.2020.v14i4.1716

Exercise endurance is a reflection of how capable the heart, lungs and blood cells are of supplying oxygenated blood to muscle tissues that are exercised; ${ }^{[1]}$ it also refers to the ability of muscles to use this oxygen to produce the necessary energy for movement. ${ }^{[1]}$ Various factors affect the exercise endurance of an individual, such as abnormalities of the cardiovascular, haematological and pulmonary systems. ${ }^{[2]}$ Untreated HIV infection can give rise to a cardiomyopathy which results in reduced exercise endurance and other complications of cardiac failure. ${ }^{[3]}$

Exercise endurance can be measured objectively using different tests. Some tests assess the body systems involved in exercise performance while others focus on the exertion during exercise. Choosing a test should be based on the variables that need to be tested and the resources available. ${ }^{[4]}$ Recently, there has been more interest shown in simple tests that link exercise testing to daily activities, such as walk tests. ${ }^{[5]}$

Exercise can have an immense impact on the exercise endurance of chronically ill patients. ${ }^{[6]} \mathrm{A}$ study examining the effects of a hospitaland home-based exercise intervention on HIV-infected children in Miami, Florida, showed improvements in aerobic capacity and lean body mass from both exercise interventions. ${ }^{[7]}$ Research on the effects of a home exercise programme (HEP) in children with HIV is limited worldwide; to date, there have been no South African studies in which a HEP has been used to improve exercise endurance in HIV-infected children. Hospital-based physiotherapists are unable to provide regular therapy to all children with HIV owing to shortages of staff at South African (SA) provincial hospitals, ${ }^{[8]}$ and consequently there is growing interest in the effect that home-based treatment programmes have on the rehabilitation outcomes for these children.
The objective of the study was to investigate the effects of a HEP on the exercise endurance of children infected with HIV. This was done by investigating the exercise endurance of children with HIV undergoing a 12-week HEP compared with the exercise endurance of children with HIV not receiving the HEP after the 12-week period. The change in exercise endurance from baseline to follow-up was also investigated within each group.

\section{Methodology}

We conducted a randomised control trial and enrolled children attending the HIV treatment clinic at Rahima Moosa Mother and Child Hospital (RMMCH) in Johannesburg. Convenience sampling was employed and children attending the clinic together with their legal guardians were approached to ascertain interest in enrolling in the study.

\section{Study population}

Sample size calculations were based on the 6MWT data collected from currently unpublished research conducted at $\mathrm{RMMCH}$. A sample of 31 children per group was calculated to provide $90 \%$ power and allowed for an attrition rate of $20 \%$. The confidence interval was 7.14 for the mean distance. Significance was set at 0.05 .

\section{Procedure}

Anthropometric data were recorded from each participant's clinic file on the day of their visit, and included their weight and height measurements. The participants' heart rate, blood pressure and oxygen saturation were measured pretest, immediately postest, and five minutes posttest. The $6 \mathrm{MWT}$ was demonstrated and carried out according to the 
standardised guidelines issued by the American Thoracic Society. ${ }^{[9]} \mathrm{A}$ $30 \mathrm{~m}$ stretch was clearly marked using two orange cones. The walk test was demonstrated by the investigator depicting how the participant needed to turn around when reaching the cone. Only standard phrases were used to encourage the participant. Each completed lap was marked on the data collection sheet. A standard measuring tape was used to measure distance walked between the cones once the 6MWT was completed and the test was stopped. A timer on a mobile phone (Samsung J5 Prime) was used to track time.

Study participants were randomly divided into an intervention and control group using a computer-generated random number table. Owing to logistical reasons, blinding of the assessor was not possible. After baseline data had been collected, the exercises making up the HEP were demonstrated to participants in the intervention group by the investigator. Participants were asked to perform each of the exercises to ensure that they were correctly performed. The number of exercise repetitions was increased consistently throughout the 12 weeks of the HEP and was marked in the exercise booklet given to participants at baseline. The parent/legal guardian was asked to monitor that the child did the exercises in the correct way at home.

An exercise checklist and information sheet was explained and given to the parent/legal guardian and their child. The time when exercises were to be done, alternative times to do the exercises (if necessary), frequency of exercises and repetitions of each exercise were explained. The clinic follow-up date, which was set at 12 weeks postbaseline, was recorded and the parent/legal guardian and participant were told that they would be seen again on this date by the investigator.

The HEP which was given to the participants in the intervention group was named 'The Super Lion Programme. A literature review was carried out to investigate the structure of existing exercise programmes for children with chronic illness of a similar age. These results were used to develop the rough draft of the HEP. A nominal group was held to validate the HEP before it was implemented. The programme included elements of pretend play, where the participant pretended to be a lion while doing each exercise. The programme consisted of five different exercises, one strengthening and four cardiovascular exercises, namely sit-ups, jumping jacks, stationary skipping, jogging on the spot and bouncing and catching a ball between two people. Exercises are described in detail in Table 1. Each exercise had an increase of two repetitions per week. All exercises needed to be completed three times a week. Each participant in the intervention group was given a $20 \mathrm{~cm}$ soft ball and a $2 \mathrm{~m}$-long skipping rope to use for their exercises.

The parent/legal guardians of participants in the intervention group were contacted once a week via phone call as a reminder to complete the HEP with their child. At the 12-week followup date, the data collection procedures and exercise endurance assessments carried out were the same as those conducted at the baseline visit.

\section{Ethical considerations}

Ethical clearance to conduct the study was obtained from the Human Research Ethics Committee (Medical) of the University of the Witwatersrand prior to commencing the study. Permission was obtained from hospital authorities to conduct the study at RMMCH. Written informed consent from the parent/legal guardian was obtained prior to conducting study-related procedures. Child assent was obtained from each participant. Participants allocated to the control group were informed that they would be given a copy of the HEP at the end of the study if it was proven to increase exercise endurance.

\section{Data analysis}

Data were analysed using an intention-to-treat analysis. Sample size calculations were done using the Excel (Microsoft Corp., USA)sample size calculator (v3_2) for continuous variables.

Demographic information was analysed using descriptive statistics. Weight-for-age (WAZ), height-for-age (HAZ) and body mass index (BMI)-for-age (BAZ) $z$-scores were calculated using World Health Organization (WHO) Child Growth Standards. An independent sample $t$-test was used to compare cardiovascular data between the two groups. A univariate analysis was used to compare differences in 6MWD scores based on the dependent variables of group and gender. The level of significance for statistical tests was set at 0.05 . Exercise endurance was measured using the $6 \mathrm{MWT}$ which was carried out at baseline and at the follow-up visit. The reference equation set out by Saad et al. ${ }^{[10]}$ was used to calculate the expected mean 6MWD for all participants. $(6 \mathrm{MWD}(\mathrm{m})=4.63 \times$ height $(\mathrm{cm})-3.53 \times$ weight $(\mathrm{kg})+10.42 \times$ age (years) + 56.32). This reference equation was chosen because the study conducted by Saad et al. ${ }^{[10]}$ was carried out using a North African population of children between the ages of 6 and 16 years which included the age group used in the present study. The study was also conducted using the guidelines set out by the American Thoracic Society. A univariate analysis was used to compare differences in $6 \mathrm{MWD}$ scores based on the dependent variables of group and gender.

\section{Results}

We enrolled 62 children infected with HIV (42\% male) and randomised the participants evenly into the intervention and control groups. Both groups had equal numbers of male $(n=13)$ and

\section{Table 1. Description of exercises making up the home exercise programme}

\begin{tabular}{lll}
\hline Exercise & Description & Number of repetitions \\
\hline Sit-up & $\begin{array}{l}\text { A sit-up with the participant's arms crossed over their chest, the } \\
\text { caregiver held the participant's feet down with both knees bent. The } \\
\text { participant had to lift their head and trunk towards their knees. }\end{array}$ & 10 \\
Jumping jack & $\begin{array}{l}\text { Participant had to jump and spread their arms and legs out with arms } \\
\text { coming up to their ears and then jump with arms and legs straight and } \\
\text { close to their body again. } \\
\text { Stationary skipping }\end{array}$ & $\begin{array}{l}\text { Using a skipping rope and jumping over the rope with both handles } \\
\text { held, both feet off the ground at a time. }\end{array}$ \\
Jogging on the spot & $\begin{array}{l}\text { Jogging on the spot, participant lifted their legs up as high as possible } \\
\text { and let their arms move with their legs. }\end{array}$ & 20 \\
Bouncing and catching a ball & $\begin{array}{l}\text { The participant stood one metre away from their caregiver/sibling and } \\
\text { bounced the ball towards the other person and caught the ball when } \\
\text { the other person bounced the ball back to them. }\end{array}$ & 10
\end{tabular}


female $(n=18)$ subjects. The mean (SD) age of children in the intervention group was $8.75(0.63)$ years (range 7.08 - 9.5 years) and $8.34(0.83)$ years (range 7.17 - 9.83 years) for children in the control group. There was no difference in mean age between the groups ( $p=0.65$ ).

At the 12-week follow-up visit, six (9.7\%) participants did not attend, two participants were in the intervention group, and four participants were in the control group. Reasons for non-attendance included participants being away on vacation $(n=3)$, had been transferred to another healthcare facility since the baseline visit $(n=2)$, and non-attendance with invalid contact details $(n=1)$. Of the 29 participants in the intervention group who attended the follow-up visit, 23 participants completed all 12 weeks of the programme.

\section{Anthropometric and cardiovascular data}

The height $(\mathrm{m})$, weight $(\mathrm{kg})$ and BMI scores as well as WAZ, HAZ and BAZ from baseline and the 12-week follow-up are shown in Table 2. No significant differences in height, weight or BMI between the control and intervention groups at the baseline and the 12-week follow-up visit were seen (all $p$-values >0.05). Cardiovascular data are shown in Table 3. No statistically significant differences were found between the groups.

\section{MWD data}

The baseline and 12-week follow-up minimum, maximum and mean 6MWD between the control and intervention groups are shown in Table 4. The 6MWD data were not normally distributed; this can be seen by looking at the Kurtosis values, which are all $>2$, for both groups at baseline and follow-up. Differences in 6MWD between sexes are shown in Table 5.

A statistically significant difference between sex for all participants $(p=0.04)$ was seen at baseline. The boys in both groups walked further (mean (SD) 449.15 (75.73) m) than the girls (mean (SD) $412.46(63.02) \mathrm{m}$ ) in both groups.

Children in the control group walked a mean of $443 \mathrm{~m}$ while children in the intervention group walked a mean of $451.9 \mathrm{~m}$ at the 12-week follow-up. There were no statistically significant differences between the groups $(p=0.16)$ or by gender $(p=0.14)$ at follow-up. When the change in 6MWD from baseline and followup was measured for each group, there were no statistically significant differences in the control $(p=0.23)$ and intervention $(p=0.91)$ groups; Fig. 1 shows the change

Table 2. Anthropometric data of the control and intervention groups at baseline and at the 12-week follow-up

\begin{tabular}{llcl}
\hline Variable & \multicolumn{2}{c}{ Group } & \\
\cline { 2 - 3 } & \multicolumn{1}{c}{ Control } & Intervention & \\
\cline { 2 - 3 } & \multicolumn{2}{c}{ Baseline, mean $(\mathrm{SD})$} & 0.82 \\
\hline Height $(\mathrm{m})$ & $1.25(0.07)$ & $1.27(0.07)$ & 0.49 \\
Weight $(\mathrm{kg})$ & $23.95(4.26)$ & $24.81(5.35)$ & 0.99 \\
BMI, kg/m & $15.44(2.0)$ & $15.43(2.48)$ & 0.89 \\
WAZ score & $-0.77(2.8)$ & $-0.75(3.2)$ & 0.59 \\
HAZ score & $-0.45(0.51)$ & $-0.36(0.54)$ & 0.75 \\
BAZ score & $-0.68(1.87)$ & $-0.69(2.4)$ & $p$-value \\
& \multicolumn{1}{c}{$\mathbf{1 2}$-week follow-up, mean (SD) } & 0.24 \\
& $1.28(0.07)$ & $1.26(0.07)$ & 0.826 \\
Height $(\mathrm{m})$ & $25.24(5.32)$ & $24.90(6.23)$ & 0.986 \\
Weight $(\mathrm{kg})$ & $15.46(1.88)$ & $15.46(2.78)$ & 0.65 \\
BMI, kg/m & $-0.32(2.81)$ & $-0.31(2.5)$ & 0.88 \\
WAZ score & $-0.67(0.45)$ & $-0.66(0.43)$ & 0.87 \\
HAZ score & $-0.43(1.77)$ & $-0.42(1.7)$ &
\end{tabular}

$\mathrm{BMI}=$ body mass index; WAZ = weight-for-age $z$-score; $\mathrm{HAZ}=$ height-for-age $\mathrm{z}$-score; $\mathrm{BAZ}=\mathrm{BMI}$-for-age $z$-score.

Table 3. Cardiovascular data during the 6MWT at baseline and follow-up

\begin{tabular}{|c|c|c|c|c|}
\hline \multicolumn{5}{|c|}{ Baseline } \\
\hline Testing point & Variable & $\begin{array}{l}\text { Intervention } \\
\text { group }(n=31) \text {, } \\
\text { mean }(\mathrm{SD})\end{array}$ & $\begin{array}{l}\text { Control group } \\
(n=31) \text {, mean } \\
\text { (SD) }\end{array}$ & $p$-value \\
\hline \multicolumn{5}{|l|}{ Pretest } \\
\hline & HR (BPM) & $84(13.58)$ & $84(14.81)$ & 0.749 \\
\hline & Male & $81(9.01)$ & $82(15.89)$ & 0.607 \\
\hline & Female & $86(16.72)$ & $86(14.24)$ & 0.656 \\
\hline \multicolumn{5}{|c|}{ Immediately posttest } \\
\hline & HR (BPM) & $93(15.02)$ & $90(13)$ & 0.565 \\
\hline & Male & $91(10.23)$ & $87(14.66)$ & 0.869 \\
\hline & Female & $95(17.86)$ & $92(11.51)$ & 0.456 \\
\hline \multicolumn{5}{|c|}{5 minutes posttest } \\
\hline & HR (BPM) & $91(19.4)$ & $93(15.8)$ & 0.422 \\
\hline & Male & $86(14.29)$ & $85(16.08)$ & 0.420 \\
\hline & Female & $93(22.89)$ & 89 (15.98) & 0.719 \\
\hline \multicolumn{5}{|c|}{ Follow-up } \\
\hline \multicolumn{5}{|l|}{ Pretest } \\
\hline & HR (BPM) & $88(11.86)$ & $85(13.68)$ & 0.450 \\
\hline & Male & $86(11.39)$ & $85(11.24)$ & 0.671 \\
\hline & Female & $87(15.58)$ & $89(14.92)$ & 0.473 \\
\hline \multicolumn{5}{|c|}{ Immediately posttest } \\
\hline & HR (BPM) & $93(9.92)$ & $93(18.03)$ & 0.962 \\
\hline & Male & $91(15.74)$ & $92(15.85)$ & 0.656 \\
\hline & Female & $99(7.38)$ & $93(18.39)$ & 0.264 \\
\hline \multicolumn{5}{|c|}{5 minutes posttest } \\
\hline & HR (BPM) & $88(14.95)$ & $84(15.38)$ & 0.195 \\
\hline & Male & $82(15.62)$ & $81(18.04)$ & 0.64 \\
\hline & Female & $87(11.64)$ & $87(14.12)$ & 0.97 \\
\hline
\end{tabular}

$6 \mathrm{MWT}=$ six-minute walk test $\mathrm{HR}=$ heart rate; $\mathrm{BPM}=$ beats per minute; $\mathrm{SD}=$ standard deviation.

in walking distance for both groups from baseline to follow-up. However, participants in the intervention group walked $9.23 \mathrm{~m}$ further than participants in the control group. Boys walked a mean of $52.11 \mathrm{~m}$ more than the girls did, regardless of the group.

The expected mean 6MWD was calculated as $644.4 \mathrm{~m}(4.63 \times 127$ (mean 
height $)-3.53 \times 25.07$ (mean weight $) \times 8.5+56.32$ (mean age $))=$ $644 \mathrm{~m}$. When compared with the calculated expected mean 6MWD for age, both the control and intervention groups walked shorter distances at baseline and at the 12-week follow-up. Participants in the control group still walked $201.73 \mathrm{~m}$ less than the expected mean at follow-up. Even though the mean 6MWD of the intervention group increased over time (mean (SD) 6MWD at 12 weeks 451.9 (64.87) $\mathrm{m}$, this group still fell short of the expected mean by $192.5 \mathrm{~m}$.

\section{Discussion}

We conducted a randomised control trial investigating the impact of a 12-week HEP on the exercise endurance of children infected with HIV.

At baseline, boys walked significantly further than girls did, regardless of the randomisation group. Gender has been reported as a factor that can affect the 6MWD. ${ }^{[11,12]}$ It has been proven that boys have greater exercise capacity and increased muscle mass and therefore will perform better in the 6MWT than girls do. ${ }^{[13]}$

No significant differences in height, weight or BMI between the control and intervention groups at the baseline were seen. WAZ, HAZ and BAZ were all within the normal healthy range. Mean

\begin{tabular}{|c|c|c|c|}
\hline Variable & Control & Intervention & $p$-value \\
\hline \multicolumn{4}{|c|}{ Baseline } \\
\hline \multicolumn{4}{|l|}{ 6MWD (m) } \\
\hline Minimum & 324.25 & 275.65 & \\
\hline Maximum & 527.0 & 554.05 & \\
\hline Mean (SD) & $429.15(56.73)$ & $432.46(82.01)$ & 0.86 \\
\hline \multirow[t]{2}{*}{ Kurtosis value } & 3.25 & 3.86 & \\
\hline & \multicolumn{2}{|c|}{ 12-week follow-up } & \\
\hline \multicolumn{4}{|l|}{ 6MWD (m) } \\
\hline Minimum & 354.8 & 352.5 & \\
\hline Maximum & 577.5 & 567.5 & \\
\hline Mean (SD) & $442.67(64.38)$ & $451.9(64.87)$ & 0.61 \\
\hline Kurtosis value & 4.28 & 3.65 & \\
\hline
\end{tabular}

6MWD values were compared with those of the healthy population, which does take into consideration the chronic illness suffered by the participants. Although participants were virally suppressed, other factors, such as neural or muscular dysfunction and lack of emotional or motivational support, ${ }^{[7]}$ may have potentially resulted in a decreased 6MWD.

No significant differences were seen in height, weight or BMI between the control and intervention groups at the 12-week followup visit were seen. WAZ, HAZ and BAZ were all within the normal healthy range. Reasons for these outcomes are consistent with those described for baseline results.

When the baseline and follow-up results were compared, it was found that, on average, participants walked further after completing the 12-week HEP. Although there were no statistically significant differences between the baseline and follow-up results in the intervention group, the participants improved their 6MWD more than participants in the control group. When investigating changes in exercise endurance within a group of participants, an increase in the mean 6MWD of statistical significance is generally less than an increase of clinical significance seen in individual participants. ${ }^{[9]} \mathrm{An}$ improvement of $70-170 \mathrm{~m}$ has been proven

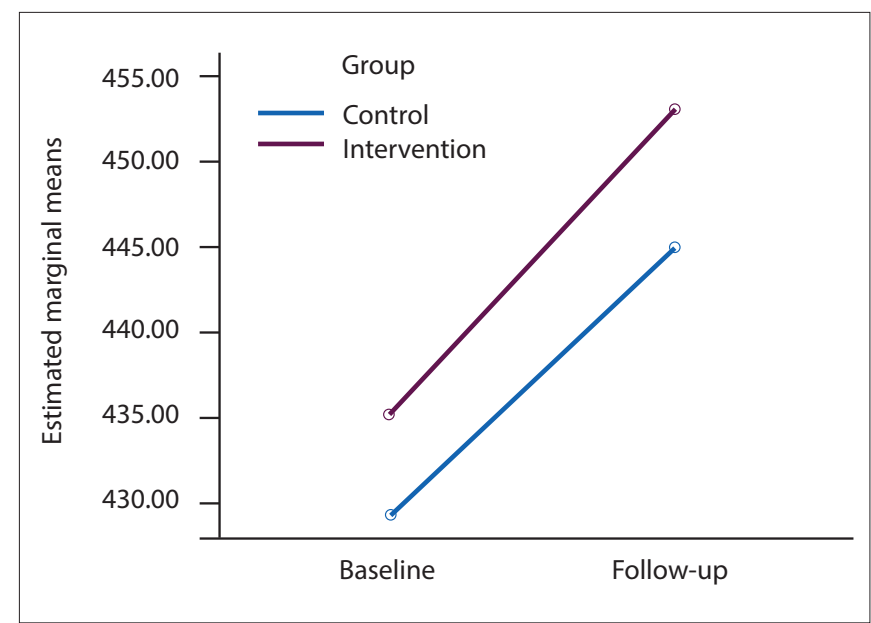

Fig. 1. Average distance walked by participants in both groups from baseline to follow-up.

Table 5. 6MWD of the control and intervention groups, showing the differences between sex, at baseline and at 12-week follow-up

\begin{tabular}{|c|c|c|c|c|c|c|}
\hline \multirow[t]{4}{*}{ Variable } & \multicolumn{6}{|c|}{ Group } \\
\hline & \multicolumn{3}{|c|}{ Control } & \multicolumn{3}{|c|}{ Intervention } \\
\hline & Male & Female & $p$-value & Male & Female & $p$-value \\
\hline & \multicolumn{6}{|c|}{ Baseline } \\
\hline \multicolumn{7}{|l|}{ 6MWD (m) } \\
\hline Minimum & 365.0 & 283.5 & & 280.0 & 271.3 & \\
\hline Maximum & 555.3 & 498.7 & & 580.0 & 528.1 & \\
\hline Mean (SD) & $442.38(57.17)$ & $415.92(56.29)$ & 0.64 & $455.91(94.28)$ & 409 (69.74) & 0.41 \\
\hline \multirow[t]{2}{*}{$p$-value (gender) } & & & & & & 0.04 \\
\hline & \multicolumn{6}{|c|}{ 12-week follow-up } \\
\hline \multicolumn{7}{|l|}{ 6MWD (m) } \\
\hline Minimum & 384.6 & 325 & & 328 & 377 & \\
\hline Maximum & 660 & 495 & & 540 & 595 & \\
\hline Mean (SD) & $464.33(74.64)$ & $421(54.11)$ & 0.32 & $456.71(69.28)$ & $447.09(60.45)$ & 0.34 \\
\hline$p$-value (gender) & & & & & & 0.14 \\
\hline
\end{tabular}


to be clinically significant. ${ }^{[12]}$ We therefore did not demonstrate clinically significant differences between the groups over the two time points. However, participants in the intervention had a greater increase in their 6MWD; this could be attributed to the HEP they had been following over the 12 -week period, resulting in improved exercise endurance.

The mean weight of the control group increased more over the 12 -week period than that of the intervention group over the same time period. This difference in weight gain may be attributed to the different exercise levels between groups, with the intervention group doing an increased amount of physical activity. Studies done to investigate the effects of a HEP on obesity found that doing cardiovascular exercise for 12 weeks resulted in a decreased amount of adipose tissue. ${ }^{[15-19]}$

The exercise programme prescribed in the present study was aimed at improving exercise endurance as this was found to improve in previous studies. A cross-sectional study conducted in Miami on children with HIV and reduced exercise endurance showed that children who were active have improved muscular strength, motor skills and cardiovascular fitness when compared with inactive children with HIV. ${ }^{[2]}$

The age range for the present study was chosen based on literature which shows that specific programmes that were structured to improve children's strength, endurance and flexibility were shown to be safe in all children who were six years and older. ${ }^{[20]}$ The period over which the exercise programme was carried out was based on previous studies conducted using exercise programmes to improve exercise endurance. A similar study was conducted by Miller et al. ${ }^{[7]}$ in 2010 on a group of $34 \mathrm{HIV}$-infected children aged six years and older. The participants completed 24 sessions over a 12 -week period exercise training programme while being supervised at the hospital, and then continued with an unsupervised home-based exercise programme. Results from the study showed clinically significant improvement in strength, flexibility, cardiorespiratory fitness and lean body mass. Exercises were structured for children with chronic illnesses and were between 60 and 90 minutes long, which was longer than the time used for the study (20 - 30 minutes). Exercise programmes described in the literature were more intense (greater number of repetitions and oxygen demand) and consisted of a larger variety of exercises, ${ }^{[7,21]}$ which may account for the fact that the intervention group in the present study did not show significant improvement in their 6MWD after the 12-week period.

At baseline and at follow-up, both groups walked less than the expected mean distance for healthy children in the same age range. This is consistent with various studies showing decreased exercise endurance in HIV-infected individuals in comparison with the healthy population. ${ }^{[6,7,14]}$ A study in Johannesburg, SA, on the exercise endurance of HIV-infected schoolgoing children aged seven to 10 years found that uninfected children in the study walked significantly further than children with HIV $(p=0.00)$.

\section{Study limitations and recommendations}

We identified certain limitations in the study, the greatest being that the 12-week period during which the HEP was carried out coincided with the December-January school holidays; this may have affected adherence to the HEP. Participants were expected to carry out the HEP over the holiday period and may have had difficulty following a routine during this time. Many participants who had caregivers who were immigrants, left the country during the holiday season to visit their home country. These participants could not be contacted telephonically to send reminders. Another limitation in the study was that there was no blinding of the investigator to the randomisation allocation owing to financial constraints and lack of human resources.

Many patients with HIV living in SA have a poor understanding of their condition, the therapy required and medication needed. ${ }^{[23]}$ The study allowed participants to be responsible for their own health, and was educational and empowering. For future studies, it is recommended to use different exercise programmes for age groups, to show the changes in exercise endurance across a wider age range; this will further substantiate the effectiveness of a HEP.

\section{Conclusion}

We conducted a 12-week randomised control trial to investigate the effects of a HEP on the exercise endurance of children infected with HIV. We compared the exercise endurance of participants doing the HEP with participants not doing the HEP. We found that a 12-week HEP has the potential to improve the distance walked in the 6MWT, even though the increase in distance from baseline to follow-up was not statistically significant in the study. Children infected with HIV doing a 12-week exercise programme have the potential to improve their exercise endurance, which may improve their quality of life.

Declaration. This manuscript was submitted in partial fulfilment of the requirements for a Masters degree at the University of the Witwatersrand.

Acknowledgements. We thank the Empliweni Services and Research Unit (ESRU) staff and patients for all their assistance, and Nikolas Pautz for his help with statistics.

Author contributions. CN collected data, analysed results and wrote the first draft of the manuscript. RS and NB-D supervised the project and reviewed all drafts. JP conceptualised the project and reviewed all drafts. Funding. None.

Conflicts of interest. None.

1. Deary IJ, Weiss A, Batty GD. Intelligence and personality as predictors of illness and death: How researchers in differential psychology and chronic disease epidemiology are collaborating to understand and address health inequalities. Psycholsci 2010;11(2):53-79. https://doi.org/10.1177/1529100610388753

2. Steele RM, Brage S, Corder K, Wareham NJ, Ekelund U. Physical activity, cardiorespiratory fitness, and the metabolic syndrome in youth. J Appl Physiol 2008;105(1):342-351. https://doi.org/10.4135/9781446222287.n7

3. Patel K, Van Dyke RB, Mittleman MA, Colan SD, Oleske JM. The impact of HAART on cardiomyopathy among children and adolescents perinatally infected with HIV-1. AIDS 2012;26(16):2027.

4. Weisman IM. Erratum: ATS/ACCP statement on cardiopulmonary exercise testing. Am J Respir Crit Care Med 2003;167(10):1451-1452. https://doi. org/10.1164/rccm.167.2.211

5. Hakestad KA, Torstveit MK, Nordsletten L, Axelsson AC, Risberg MA. Exercise including weight vests and a patient education program for women with osteopenia: A feasibility study of the OseoActive rehabilitation program. J Orthop Sports Phys Ther 2015;45(2):97-105. https://doi.org/10.2519/ jospt.2015.4842

6. Baigis J, Korniewicz DM, Chase G, Butz A, JacobsonD, Wu AW. Effectiveness of a home-based exercise intervention for HIV-infected adults: A randomized trial. J Assoc Nurses AIDS Care 2002;13(2):33-45. https://doi.org/10.1016/s1055$3290(06) 60199-4$

7. Miller TL, Somarriba G, Kinnamon DD, Weinberg GA, Friedman LB, Scott GB. The effect of a structured exercise program on nutrition and fitness outcomes in human immunodeficiency virus-infected children. AIDS Res Hum Retroviruses 2010;26(3):313-319. https://doi.org/10.1089/ aid. 2009.0198

8. Potterton J, Stewart A, Cooper P, Goldberg L, Gajdosik C, Baillieu $\mathrm{N}$. Neurodevelopmental delay in children infected with human immunodeficiency virus in Soweto, South Africa. Vulnerable Children and Youth Studies 2009;4(1):48-57. https://doi.org/10.1080/17450120802183728

9. Travis WD, King TE, Bateman ED, et al. American Thoracic Society/ European Respiratory Society international multidisciplinary consensus classification of the idiopathic interstitial pneumonias. Am J Respir Crit Care 
Med 2002;165(2):277-304. https://doi.org/10.1164/ajrccm.165.2.ats01

10. Saad HB, Prefaut C, Missaoui R, Mohamed IH, Tabka Z, Hayot M. Reference equation for 6-min walk distance in healthy North African children 6-16 years old. Pediatr Pulmonol 2009;44(4):316-324. https://doi.org/10.1002/ ppul. 20942

11. Enright PL. The six-minute walk test. Respir Care 2003:48(8):783-785.

12. Ulrich S, Hildenbrand FF, Treder U, et al. Reference values for the 6-minute walk test in healthy children and adolescents in Switzerland. BMC Pulmon Med 2013;13(1):49. https://doi.org/10.1007/springerreference_184598

13. Li A, Yin J, Yu C, et al. The six-minute walk test in healthy children: Reliability and validity. Eur Respir J 2005;25(6):1057-1060. https://doi.org/10.1183/0903 1936.05.00134904

14. Somarriba G, Neri D, Schaefer N, Miller TL. The effect of aging, nutrition and exercise during HIV infection. HIV AIDS 2010;2(12):191-201. https:// doi.org/10.2147/hiv.s9069

15. Carrel AL, Clark RR, Peterson SE, Nemeth BA, Sullivan J, Allen DB. Improvement of fitness, body composition, and insulin sensitivity in overweight children in a school-based exercise program: A randomized, controlled study. Arch Pediatr Adolesc Med 2005;159(10):963-968. https:// controlled study. Arch Pediatr Adolesc

16. Meyer AA, Kundt G, Lenschow U, Schuff-Werner P, Kienast W. Improvement of early vascular changes and cardiovascular risk factors in obese children after a six-month exercise program. J Am Coll Cardiol 2006;48(9):1865-1870. https://doi.org/10.1016/j.jacc.2006.07.035

17. Savoye M, Shaw M, Dziura J, et al. Effects of a weight management program on body composition and metabolic parameters in overweight children: A randomized controlled trial. JAMA 2007;297(24):2697-2704.
18. Lee YH, Song YW, Kim HS, et al. The effects of an exercise program on anthropometric, metabolic, and cardiovascular parameters in obese children. Korean Circ J 2010;40(4):179-184. https://doi.org/10.1001/jama.297.24.2697

19. Davis CL, Cooper S. Fitness, fatness, cognition, behavior, and academic achievement among overweight children: Do cross-sectional associations correspond to exercise trial outcomes? Prev Med 2011;52:S65-S69. https:// doi.org/10.1016/j.ypmed.2011.01.020

20. Faigenbaum AD. Strength training for children and adolescents.Clin Sports Med 2000;19(4):593-619. https://doi.org/10.1007/978-3-319-75547-2_17

21. Stephen S, Feldman BM, Bradley N, et al. Feasibility and effectiveness of an aerobic exercise program in children with fibromyalgia: Results of a randomized pilot trial. J Am Coll Rheum 2008;5(10):1399-1406. https://doi. org/10.1002/art.24115

22. Kalitanyi V, Visser K. African immigrants in South Africa: Job takers or job creators? S Afr J Econ Man Sci 2010;13(4):376-390. https://doi.org/10.4102/ sajems.v13i4.91

23. Cobbing S, Hanass-Hancock J, Deane M. Physiotherapy rehabilitation in the context of HIV and disability in KwaZulu-Natal, South Africa. Disabil Rehabil 2014;36(40):1687-1694. https://doi.org/10.3109/09638288.2013.87 2199

Accepted 8 June 2020. 